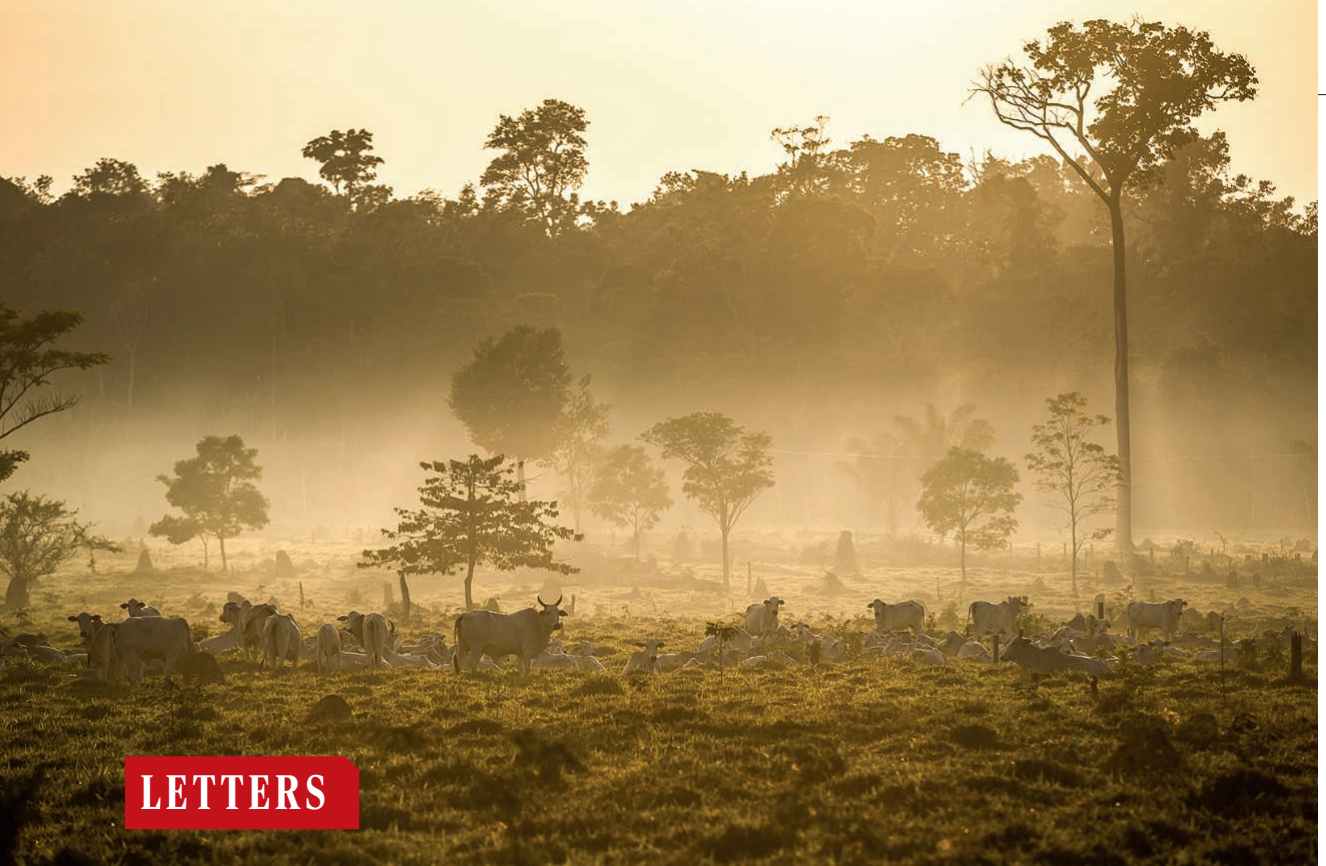

Edited by Jennifer Sills

\section{Make EU trade with Brazil sustainable}

Brazil, home to one of the planet's last great forests, is currently in trade negotiations with its second largest trading partner, the European Union (EU). We urge the EU to seize this critical opportunity to ensure that Brazil protects human rights and the environment.

Brazil's forests, wetlands, and savannas are crucial to a great diversity of Indigenous peoples, the stability of our global climate, and biodiversity conservation (1). By working toward dismantling anti-deforestation policies, Brazil's new administration threatens Indigenous rights and the natural areas they protect (2).

The EU spent more than $€ 3$ billion on Brazilian iron imports in 2017 (3), despite perilous safety standards and extensive deforestation driven by mining (4). In 2011 alone, the EU imported beef and livestock feed associated with more than $1000 \mathrm{~km}^{2}$ of Brazilian deforestation [equivalent to more than 300 football fields per day (5)]. The EU thus urgently needs to strengthen efforts on sustainable trade (6-8) and uphold its commitments on human rights, environmental protection, and climate change mitigation (9).

Halting deforestation makes economic sense, as intact forests are critical to maintaining the rainfall patterns on which Brazilian agriculture depends (10). Restoring degraded lands and improving yields could meet rising agricultural demand for at least two decades without need for further forest clearance (11).

We urge the EU to make trade negotiations with Brazil conditional on: (i) upholding the United Nations Declaration on the Rights of Indigenous Peoples; (ii) improving procedures to trace commodities associated with deforestation and Indigenous rights conflicts; and (iii) consulting with, and gaining consent from, Indigenous Peoples and local communities to define strict social and environmental criteria for traded commodities.

The EU was founded on the principles of respecting human rights and human dignity. Today, it has the opportunity to be a global leader in supporting these principles and a habitable climate by making sustainability the cornerstone of its trade negotiations with Brazil.

Laura Kehoe'*, Tiago Reis ${ }^{2}$, Malika Virah-Sawmy ${ }^{3}$, Andrew Balmford", Tobias Kuemmerle ${ }^{3}$, and 604 signatories $\dagger$ ${ }^{1}$ Oxford Martin School, University of Oxford, Oxford OX1 3BD, UK. ${ }^{2}$ Earth and Life Institute, Université Catholique de Louvain, Louvain-laNueve, Belgium. ${ }^{3}$ Conservation Biogeography Lab, Humboldt-Universität zu Berlin, 10099 Berlin, Germany. ${ }^{4}$ Conservation Science Group, University of Cambridge Conservation Research Institute, Cambridge CB2 8QZ, UK

*Corresponding author

Email: laurajkehoe@gmail.com

+Signatories include 602 European scientists and 2 Brazilian Indigenous organizations, which together represent 300 Brazilian Indigenous groups. The full list of signatories is available online.

\section{REFERENCES AND NOTES}

1. T.H. Ricketts etal.,PLOSBiol.8, e1000331(2010).

2. D. Abessa, A. Famá, L. Buruaem, Nat. Ecol. Evol. 3,510 (2019).

3. Eurostat,"Brazil-EU-International trade in goods statistics" (2018), Figure 7; https://ec.europa.eu/ eurostat/statistics-explained/index.php?title=BrazilEU___international_trade_in_goods_statistics\#Most_ traded_goods:_aircraft_and_associated_equipment.

4. L.J.Sonter etal.,Nat. Commun. 8,1013(2017)

5. S. Henders, U. M. Persson, T. Kastner, Environ. Res. Lett. 10, 125012(2015)

6. European Commission, “Deforestation and forest degradation-Stepping up EU action"(2018); https:// ec.europa.eu/info/law/better-regulation/initiatives/ ares-2018-6516782_en.
Rainforest gives way to pastures in the

Brazilian Amazon in Mato Grosso.

7. Amsterdam Declarations Partnership (2018); https://adpartnership.org/about/.

8. European Commission, "Implementation of the trade and sustainable development (TSD) chapter in trade agreements-TSD committees and civil society meetings" (2019); http://trade.ec.europa.eu/doclib/press/index. cfm?id=1870.

9. European Parliament,"Transparent and accountable management of natural resources in developing countries: The case of forests"(2019); www.europarl. europa.eu/sides/getDoc.do?pubRef=-//EP// NONSGML+TA+P8-TA-2018-0333+0+DOC+PDF+V0//EN .

10. D. Lawrence, K. Vandecar, Nat. Clim. Chang. 5,27(2014)

11. B. B.N.Strassburgetal., Glob. Environ. Chang. 28,84(2014).

SUPPLEMENTARY MATERIALS

science.sciencemag.org/content/364/6438/341.1/suppl/DC1 Full list of signatories

10.1126/science.aaw8276

\section{Evidence supports prediabetes treatment}

In his News Feature on prediabetes ("Dubious diagnosis," 8 March, p. 1026), C. Piller asserts that prediabetes diagnoses and treatment may be ineffective and sullied by conflicts of interest. As current and former chairs of the American Diabetes Association's (ADA's) Professional Practice Committee [the group that reviews and updates the Standards of Medical Care in Diabetes (Standards) each year], we disagree. Prediabetes is a useful term to convey future risk of diabetes, and recommendations for diabetes prevention are based on best current evidence.

The ADA classifies prediabetes as a risk factor for diabetes that can be mitigated by lifestyle changes or, in limited circumstances, with the addition of metformin. Piller reports that prediabetes does little or no harm on its own and that fewer than $2 \%$ of people with prediabetes progress to diabetes each year. The risk of progressing from prediabetes to diabetes varies according to the diagnostic criteria used (1), but even a $2 \%$ progression rate per year would translate to nearly 1 of 5 people with prediabetes developing diabetes within 10 years. Also, many individuals with prediabetes have a multiplicity of risk, due to ethnicity, body weight, and other factors, and these may render their annual risk much higher.

In the online "Key takeaways" box (https://scim.ag/prediabetes), Piller states that "Many studies suggest that for most people the usual treatments for prediabetes, diet and exercise, do little to further reduce the risk of diabetes." However, healthy eating and regular physical activity (2) have been shown (along with the medication 
metformin for select patients) to delay or prevent progression to diabetes (3-5). Accordingly, the Standards place a heavy emphasis on these lifestyle interventions.

Piller writes that the ADA lists costly medications for diabetes prevention, sold by pharmaceutical companies from which Professional Practice Committee members have collected "large sums." We disagree that this funding affected the committee's positions. No pharmaceutical agents have been FDA-approved for diabetes prevention, and the only recommended medication is metformin, which has been shown to be effective and safe $(3,6)$ and is available for as little as $\$ 4$ per month [e.g., (7)], rendering the conflicts of interest described in the article irrelevant to the current ADA recommendations for diabetes prevention. In fact, metformin may save costs over a 10 -year period when used for diabetes prevention (6). The Standards of Care mentions pharmacologic agents other than metformin, including glucose-lowering and weight loss therapies that have been studied for diabetes prevention (3), but these agents are not recommended by the ADA for diabetes prevention. Additionally, the ADA states that metformin should be considered for those who have prediabetes, especially those who have a body mass index (BMI) of at least $35 \mathrm{~kg} / \mathrm{m}^{2}$, are under the age of 60 years, or have a history of gestational diabetes mellitus (2). These recommendations highlight the importance of risk stratification and individualization of therapy.

We acknowledge that unanswered questions surrounding prediabetes and its management remain important issues that warrant open discussion. Indeed, the ADA has not shied away from such debate $(8,9)$. It is important to engage in these discussions with full consideration of the available evidence.

Joshua J. Neumiller ${ }^{1 *}$, Rita R. Kalyani ${ }^{2}$,
William H. Herman $^{3}$, Richard W. Grant'
Carol H. Wysham
, Silvio E. Inzucchi
Irl B. Hirsch, Buse $^{9}$, Eugene J. Barrett ${ }^{10}$

'Department of Pharmacotherapy, College of Pharmacy and Pharmaceutical Sciences, Washington State University, Spokane, WA 99202, USA. ²Division of Endocrinology, Diabetes, and Metabolism, Johns Hopkins University School of Medicine, Baltimore, MD 21287, USA. ${ }^{3}$ Department of Internal Medicine, University of Michigan, Ann Arbor, Ml 48105-1912, USA. ${ }^{4}$ Division of Research, Kaiser Permanente Northern California, Oakland, CA 94612, USA. ${ }^{5}$ Multicare Rockwood Clinic, Spokane, WA 99202. USA. ${ }^{6}$ Yale School of Medicine, New Haven, CT 06520-8020, USA. 7University of Washington Medical Center. Seattle, WA 98105, USA. ${ }^{\text {SSection }}$ of Endocrinology, Tulane University Health Sciences Center, New Orleans, LA 70112, USA. PUniversity of North Carolina School of Medicine, Chapel Hill, NC 27599, USA. ${ }^{10}$ Division of Endocrinology and Diabetes, University of Virginia, Charlottesville, VA 22903, USA. *Corresponding author. Email: jneumiller@wsu.edu
REFERENCES AND NOTES

1. M. I.Schmidt et al., Lancet Diabetes Endocrinol.10.1016/ S2213-8587(19)30058-0 (2019).

2. American Diabetes Association, Diabetes Care $\mathbf{4 2}$ (suppl. 1), S29 (2019).

3. W. C. Knowler etal., N. Engl. J.Med.346,393 (2002)

4. J.Lindströmetal., Lancet 368, 1673 (2006).

5. G. Liet al.,Lancet Diabetes Endocrinol. 2, 474 (2014).

6. Diabetes Prevention Program Research Group, Diabetes Care 35, 723 (2012).

7. Walmart, $\$ 4$ prescriptions (www.walmart.com/ $\mathrm{cp} / \$ 4$-prescriptions/1078664).

8. W. T. Cefalu, Diabetes Care 39,1472 (2016)

9. J.S. Yudkin, Diabetes Care 39,1468 (2016)

\section{COMPETING INTERESTS}

W.H.H. serves as chair for a Data Safety Monitoring Board for Merck Sharp \& Dohme. C.H.W. receives institutional research support from Mylan and Novo Nordisk; she has received honoraria from Abbott, AstraZeneca, Boehringer Ingelheim, Dexcom, Janssen, Novo Nordisk, and Sanofi. S.E.I. has served as a consultant to Boehringer Ingelheim, AstraZeneca, Novo Nordisk, Sanofi/Lexicon, and Eisai (TIMI) and has lectured for Boehringer Ingelheim. I.B.H. receives institutional research support from Medtronic Diabetes and serves as a consultant for Abbott Diabetes Care, Roche, Bigfoot, and Becton Dickinson. V.A.F. declares a duality of interest: research support (to Tulane) (grants from Bayer and Boehringer Ingelheim), honoraria for consulting and lectures (Takeda, Novo Nordisk, Sanofi-Aventis, Eli-Lilly, Abbott, Astra-Zeneca, Intarcia, and Asahi), stock options (Microbiome Technologies, Insulin Algorithms, and BRAVO4Health), and stock (Amgen). J.B.B.'s contracted consulting fees are paid to the University of North Carolina by Adocia, AstraZeneca, Dance Biopharm, Dexcom, Elcelyx Therapeutics, Eli Lilly, Fractyl, GI Dynamics, Intarcia Therapeutics, Lexicon, MannKind, Metavention, NovaTarg Novo Nordisk, Orexigen, PhaseBio, Sanofi, Senseonics, Shenzhen HighTide, Takeda, vTv Therapeutics, and Zafgen; he reports grant support from AstraZeneca, Eli Lilly, GI Dynamics, GlaxoSmithKline, Intarcia Therapeutics, Johnson \& Johnson, Lexicon, Medtronic, Novo Nordisk, Orexigen, Sanofi, Scion NeuroStim, Takeda, Theracos, and vTv Therapeutics; he is a consultant to Cirius Therapeutics Inc., CSL Behring, and Neurimmune AG; he holds stock or options in Mellitus Health, PhaseBio, and Stability Health.

10.1126/science.aax3548

\section{Pay to protect at-risk bycatch species}

The incidental capture of threatened species as bycatch is placing global biodiversity at risk $(1,2)$, particularly in developing countries where small-scale fishing and hunting often rely on unselective capture methods (3, 4). To address this, the Indian Maharashtra state government recently announced that

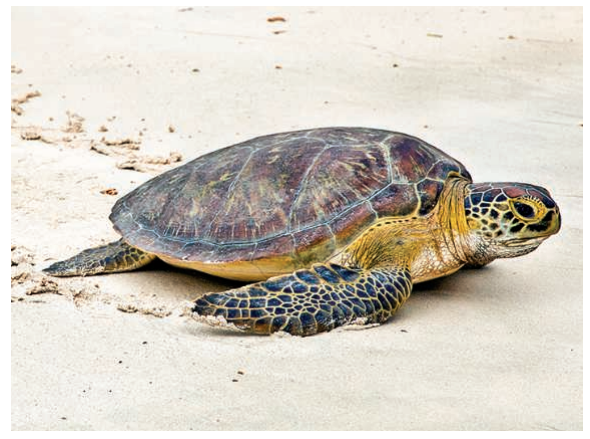

India is emulating Kenya's bycatch release program, which protects endangered green sea turtles. it will financially compensate fishers who release incidentally captured endangered species. Payment will be made based on photographic evidence of the captured individual and proof that fishing gear was damaged to allow the release (5).

Financially incentivizing the release of threatened bycatch considers the needs of fishers and hunters whose actions often have direct consequences for conservation $(6,7)$. As a result of a similar pay-forrelease program, Kenyan fishers have released about 17,000 threatened bycaught sea turtles over the past two decades (8). This positive outcome underscores clear and measurable conservation gains, yet pay-for-release schemes remain a rarely used conservation strategy.

Instead, tackling the issue of bycatch mostly relies on modifying capture gear, education, and enforcing legislation ( 1 , 2,9 ), approaches that commonly require long-term investment for positive outcomes $(3,4,10)$. The pay-for-release strategy could provide a rapid, complementary mechanism to ease pressure on threatened species, such as sawfishes (11), that are not the focus of harvest and require immediate conservation action $(5,12)$. The Maharashtra government, and any local governments that follow suit, should explore a broad range of scenarios and collect results to determine the most effective way to implement this type of program and to assess its effectiveness.

\section{Antoine O. H. C. Leduc ${ }^{1 *}$ and}

\section{Nigel E. Hussey}

Post-Graduation Program in Ecology, Department of Oceanography and Limnology, Universidade Federal do Rio Grande do Norte, Natal, RN, 59014002. Brazil. ${ }^{2 B}$ Biological Sciences, University of Windsor, Windsor, ON N9B 3P4, Canada.

*Corresponding author.

Email: mirabiles@hotmail.com

\section{REFERENCES AND NOTES}

1. R. Lewison, L. B. Crowder, A. J. Read, S. A. Freeman, Trends Ecol. Evol.19,598(2004)

2. R. Corlett, Biotropica. 39, 292 (2007)

3. E. J. Milner-Gulland, E. L. Bennett, Trends Ecol. Evol.18, 351 (2003).

4. M. Becker etal.,Biol. Conserv. 158,26 (2013)

5. C. Marpakwar, "Fisherman, who save rare marine animals caught in their nets to get compensation," Mumbai Mirror (2018); https://mumbaimirror.indiatimes.com/ mumbai/other/fisherman-who-save-rare-marineanimals-caught-in-their-nets-to-get-compensation/ articleshow/67204916.cms?

6. P. J. Ferraro, A. Kiss, Science 298, 1718 (2002).

7. M.R.W. Rands et al., Science 329,1298 (2010).

8. Local Ocean Conservation, Bycatch Release (https:// localocean.co/bycatch-release-programme/)

9. L.M.Komoroske, R. L. Lewison, Front. Mar. Sci. 2.1(2015).

10. J.Senko, E. R. White, S. S. Heppell, L. R. Gerber, Anim. Conserv. 17.719 (2013)

11. L.R. Harrison, N. K. Dulvy, “Sawfish: Aglobal strategy for conservation" (IUCN Species Survival Commission's Shark Specialist Group, 2014).

12. A. O. H. C. Leduc, N. E. Hussey, Conserv. Biol.10.1111/ cobi.13300 (2019). 


\section{Science}

\section{Make EU trade with Brazil sustainable}

Laura Kehoe, Tiago Reis, Malika Virah-Sawmy, Andrew Balmford, Tobias Kuemmerle and 604 signatories

Science 364 (6438), 341.

DOI: $10.1126 /$ science.aaw8276

ARTICLE TOOLS

SUPPLEMENTARY MATERIALS

REFERENCES

PERMISSIONS http://science.sciencemag.org/content/364/6438/341.1

http://science.sciencemag.org/content/suppl/2019/04/24/364.6438.341-a.DC1

This article cites 6 articles, 0 of which you can access for free http://science.sciencemag.org/content/364/6438/341.1\#BIBL

http://www.sciencemag.org/help/reprints-and-permissions

Science (print ISSN 0036-8075; online ISSN 1095-9203) is published by the American Association for the Advancement of Science, 1200 New York Avenue NW, Washington, DC 20005. The title Science is a registered trademark of AAAS.

Copyright @ 2019 The Authors, some rights reserved; exclusive licensee American Association for the Advancement of Science. No claim to original U.S. Government Works 